OPEN ACCESS

Edited by:

Stéphane Joost,

École Polytechnique Fédérale de Lausanne, Switzerland

Reviewed by:

Brittany Huntington, Pacific Islands Fisheries Science Center (NOAA), United States

${ }^{*}$ Correspondence:

Tarik C. Gouhier tarik.gouhier@gmail.com

Specialty section:

This article was submitted to Conservation,

a section of the journal

Frontiers in Ecology and Evolution

Received: 30 March 2019

Accepted: 21 May 2019

Published: 05 June 2019

Citation:

Gouhier TC and Pillai P (2019)

Commentary: Tropical fish diversity enhances coral reef functioning across

multiple scales.

Front. Ecol. Evol. 7:212 doi: $10.3389 /$ fevo.2019.00212

\section{Commentary: Tropical fish diversity enhances coral reef functioning across multiple scales}

\author{
Tarik C. Gouhier* and Pradeep Pillai \\ Marine Science Center, Northeastern University, Nahant, MA, United States
}

Keywords: biodiversity, ecosystem functioning, spurious correlation, statistical interaction, spatial insurance effect

\section{A Commentary on}

Tropical fish diversity enhances coral reef functioning across multiple scales by Lefcheck, J. S., Innes-Gold, A. A., Brandl, S. J., Steneck, R. S., Torres, R. E., and Rasher, D. B. (2019). Sci. Adv. 5:eaav6420. doi: 10.1126/sciadv.aav6420

Lefcheck et al. (2019) sought to show the beneficial effects of tropical fish biodiversity on coral reef ecosystem functioning at multiple scales. To do so, they collected data from video and transect surveys at 10 sites to determine whether $\alpha$ and $\beta$ species diversity of fish led to an increase in ecosystem functioning in the form of higher grazing rates at multiple scales and whether grazing rates enhanced ecosystem structure by reducing turf abundance and promoting coral abundance. Below, we describe a number of major conceptual and statistical flaws in their study that undermine their results and conclusions.

\section{GRAZING RATE IS AN INAPPROPRIATE MEASURE OF ECOSYSTEM FUNCTIONING}

The first conceptual issue lies in the use of the grazing rate (bite rate) as a measure of ecosystem functioning. Such increased grazing of turf can promote ecosystem functioning if it reduces turf abundance and thus leads to an increase in reef-building corals via competitive release. Ecosystem functioning should thus be measured in terms of the impact of grazing on turf or coral rather than its rate. Grazing rate, on its own, is merely one of an infinite number of community or system-level properties that could also be arbitrarily designated as "ecosystem functions." Its relevance arises only due to its potential impact on an ecosystem property of interest. Showing a significant positive relationship between various diversity metrics and grazing rate is thus necessary but not sufficient to demonstrate greater ecosystem functioning.

Yet the mixed-effects model in Lefcheck et al. showed no relationship between massstandardized bite rate and either turf cover or coral cover in the video dataset (Figures 1A,B). The lack of a relationship suggests that changes in the mass-standardized bite rate do not translate into changes in turf or coral cover. Additionally, no relationship emerges when the mass-standardized bite rate is regressed against turf cover rather than turf height in the transect dataset (Figure 1C). Similarly, no relationship exists when regressing juvenile coral recruitment against turf cover (Figure 1D). This means that the entire case for a meaningful effect of bite rate on ecosystem functioning emerges only when turf height (not cover) is used in one of the two datasets. Although the relationship between turf height and juvenile coral recruitment may represent one of the many 

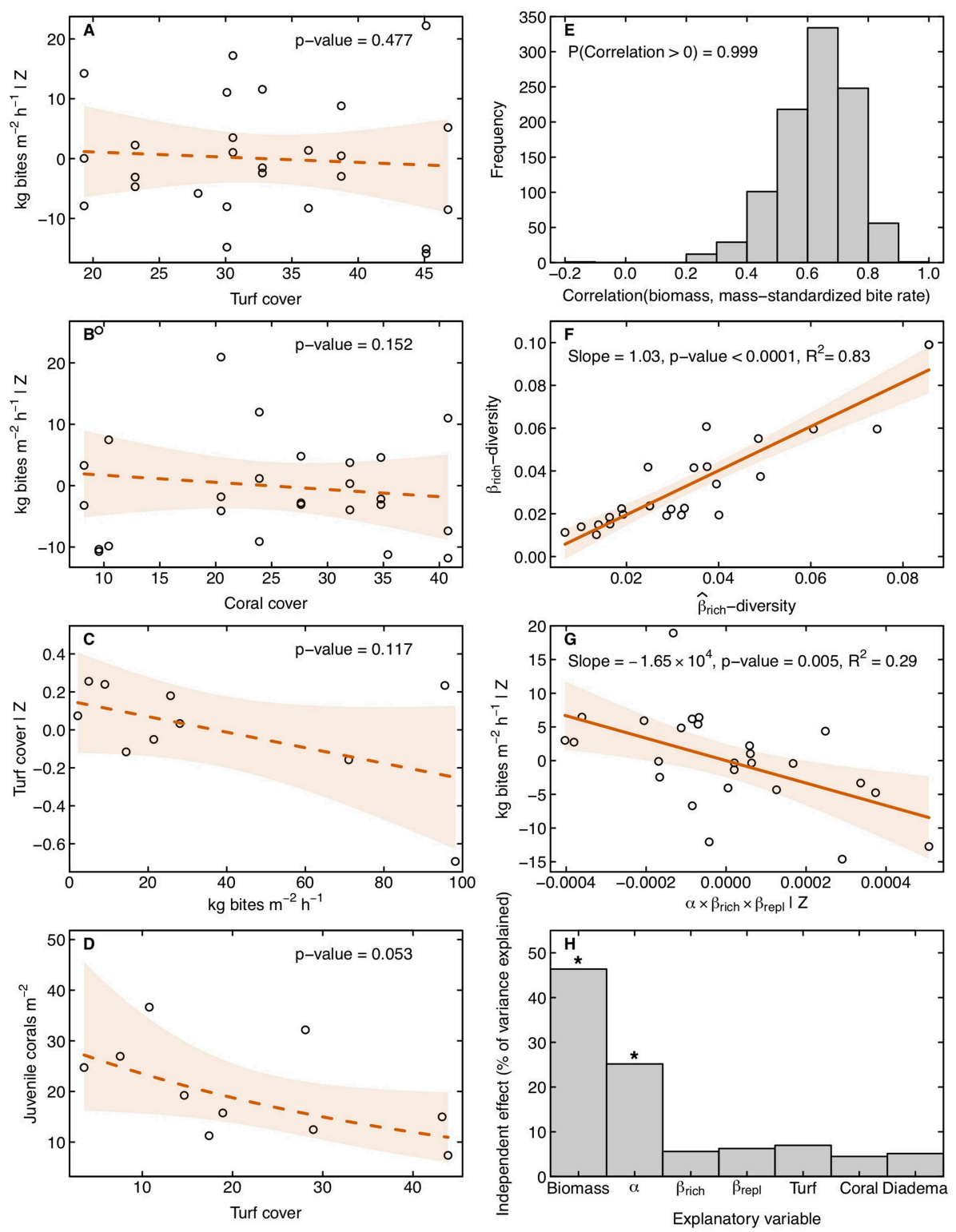

FIGURE 1 | Statistical issues with the relationship between mass-standardized bite rate, species diversity and ecosystem functioning. No relationship between mass-standardized bite rate and turf cover $(\mathbf{A})$ or coral cover $\mathbf{( B )}$ in the video dataset. No relationship between mass-standardized bite rate and turf cover $(\mathbf{C})$ or between turf cover and juvenile coral density (D) in the transect dataset. (E) Distribution of spurious correlations induced between biomass and mass-standardized bite rate when biomass and bite rate are independent random variables drawn from a uniform distribution across 1,000 Monte Carlo simulations. (F) Collinearity between diversity metrics shown via a significant positive relationship between $\beta_{\text {rich }}$ observed and $\hat{\beta}_{\text {rich }}$ predicted from a multiple regression of $\beta_{\text {rich }}$ against $\alpha$ and $\beta_{\text {repl }}$ explaining $83 \%$ of the variance. (G) Significant negative partial effect of the three-way interaction between $\alpha, \beta_{\text {rich }}$, and $\beta_{\text {repl }}$ diversity on the mass-normalized bite rate. (H) The independent effect of each explanatory variable as a percentage of the variance explained in the mass-normalized bite rate. The model explains $89 \%$ of the total variance. Asterisks indicate statistically significant variables ( $p$-value $<0.05)$.

facets of the competitive interaction between both species, this competition should ultimately lead to a negative relationship between turf and coral cover, and thus a positive relationship between bite rate and coral cover. However, the lack of a positive relationship between bite rate and coral cover in either the video or the transect data suggests that fish biodiversity does not influence ecosystem functioning.

\section{NO EVIDENCE THAT DIVERSITY PROMOTES ECOSYSTEM FUNCTIONING ACROSS SCALES}

The second conceptual issue stems from the claim that diversity promotes ecosystem functioning across scales and the suggestion that the results presented in Lefcheck et al. are consistent 
with the spatial insurance hypothesis. Spatial insurance effects (sensu Loreau et al., 2003) occur when ecosystem functioning is enhanced and more stable at the regional scale as a result of local sites undergoing favorable conditions rescuing those undergoing unfavorable ones. Because spatial insurance effects emerge at the regional scale, they cannot be detected by regressing local ecosystem functioning against local factors such as diversity and biomass across all sites. Although the results presented in Lefcheck et al. show that localized measures of diversity promote local ecosystem functioning, this local-scale effect was misinterpreted as evidence of a multi-scale effect because it arose at multiple sites. However, observing a biodiversity effect at multiple sites is not the same as observing it at multiple scales. Demonstrating a multi-scale effect would require aggregating the data across sites in order to quantify the relationship between biodiversity and ecosystem functioning at progressively larger spatial scales (e.g., Winfree et al., 2018).

\section{INEVITABLE RELATIONSHIPS BETWEEN BIOMASS, DIVERSITY, AND BITE RATE}

The mixed-effects model presented in Lefcheck et al. showed a significant positive relationship between mass-standardized bite rate and biomass. However, this relationship is at least partially attributable to a spurious correlation because the response variable is the bite rate scaled by the explanatory variable (biomass). Monte Carlo simulations show that this leads to spurious correlations between mass-standardized bite rate and biomass when biomass and bite rate are independent random variables drawn from a uniform distribution (Figure 1E). When the spurious correlation issue is fixed by using the non-massstandardized bite rate as a response variable, the positive effect of biomass remains significant but that is because biomass is acting as a surrogate for the number of fish observed at each site (correlation $=0.97, p$-value $<0.0001$ ). A positive relationship between biomass and bite rate was to be expected since increasing the number of fish leads to both greater total biomass and a larger number of total bites.

A similar issue arises with $\alpha$ diversity, which was also positively associated with bite rate. This was interpreted as a local diversity effect, with more species yielding a higher total bite rate, perhaps because of complementarity in resource use between fish species. However, the relationship between total bite rate and $\alpha$ diversity was bound to be positive since increasing $\alpha$ diversity is largely tantamount to increasing the total number of fish as long as the community is not saturated. Because increasing species richness leads to an increase in the number of fish (correlation $=0.54, p$-value $=0.007$ ), and adding individual fish will increase the total number of bites, the relationship between total bite rate and $\alpha$ diversity essentially has to be positive. Hence, since $\alpha$ diversity is at least partially acting as a surrogate for the total number of fish, it is not surprising to see a positive relationship emerge between total bite rate and $\alpha$ diversity. However, this is likely due to a population size effect rather than a true species diversity effect. Indeed, when the effect of population size is controlled for by first regressing the mass-standardized bite rate against the number of fish, the residual mass-standardized bite rate is unrelated to either biomass ( $p$-value $=0.49$ ) or $\alpha$ diversity $(p$-value $=0.2)$.

\section{SPURIOUS RELATIONSHIP BETWEEN $\beta_{R I C H}$ DIVERSITY AND BITE RATE}

Lefcheck et al. found a positive relationship between local bite rate and a site's compositional uniqueness ( $\beta_{\text {rich }}$ diversity) and claimed that it represented evidence of an effect of biodiversity on ecosystem functioning across scales. There is no clear mechanism by which higher $\beta_{\text {rich }}$ diversity can lead to a higher bite rate at the local scale, as the positive effects of $\beta_{\text {rich }}$ diversity on bite rate can only emerge when sites are aggregated at larger spatial scales. Any positive effect of a site's $\beta_{\text {rich }}$ diversity on local bite rate would be captured by local factors. It is more likely that the positive effect of $\beta_{\text {rich }}$ diversity on local bite rate described by Lefcheck et al. is due to multicollinearity between the explanatory variables $\alpha, \beta_{\text {repl }}$, and $\beta_{\text {rich }}$ diversity included in the mixed-effects model (Figure 1F). Furthermore, perhaps under the mistaken impression that the additive partitions of total $\beta$ diversitynamely $\beta_{\text {repl }}$ and $\beta_{\text {rich }}$-had to be orthogonal, the authors verified that all possible two-way interactions between $\alpha$ diversity and the components of $\beta$ diversity were not significant but failed to test and include the significant three-way interaction between $\alpha, \beta_{\text {repl }}$, and $\beta_{\text {rich }}$ diversity in their model ( $p$-value $=0.03$ ). The coefficient associated with this significant three-way interaction is negative, so an increase in any of the three diversity metrics will lead to a reduction in the mass-standardized bite rate (Figure 1G). Standard statistical practice dictates that in the presence of such a significant negative three-way interaction, the positive main effects of $\alpha$ and $\beta_{\text {rich }}$ diversity that constitute the backbone of Lefcheck et al.'s conclusions should not be interpreted because their independent effects on mass-standardized bite rate are not consistent (Zar, 1999; Quinn and Keough, 2002; Whitlock and Schluter, 2008; Sokal and Rohlf, 2011). To verify this claim, we used hierarchical partitioning (Chevan and Sutherland, 1991; Mac Nally, 2000) to determine the independent effect of each explanatory variable on mass-standardized bite rate and found that only biomass and $\alpha$ diversity were significant and collectively represented $72 \%$ of the variance explained, whereas $\beta_{\text {rich }}$ and $\beta_{\text {repl }}$ diversity were not significant and collectively represented only $12 \%$ of the variance explained (Figure $\mathbf{1 H}$ ). This is not surprising since the positive effects of $\beta$ diversity cannot emerge at the local scale.

\section{CONCLUSION}

Overall, we believe that the conceptual and statistical issues outlined above demonstrate that there is no evidence that fish diversity promotes ecosystem functioning across scales. Establishing this important result would require linking $\alpha$ and $\beta$ diversity to greater ecosystem functioning in the form of higher coral cover or lower turf cover beyond the local scale by aggregating the data across sites as other researchers have done (Winfree et al., 2018). 


\section{AUTHOR CONTRIBUTIONS}

TG performed the analyses and wrote the manuscript with input from PP.

\section{REFERENCES}

Chevan, A., and Sutherland, M. (1991). Hierarchical partitioning. Am. Stat. $45,90-96$.

Lefcheck, J. S., Innes-Gold, A. A., Brandl, S. J., Steneck, R. S., Torres, R. E., and Rasher, D. B. (2019). Tropical fish diversity enhances coral reef functioning across multiple scales. Sci. Adv. 5:eaav6420. doi: 10.1126/sciadv.a av6420

Loreau, M., Mouquet, N., and Gonzalez, A. (2003). Biodiversity as spatial insurance in heterogeneous landscapes. Proc. Natl. Acad. Sci. U.S.A. 100, 12765-12770. doi: 10.1073 /pnas. 2235465100

Mac Nally, R. (2000). Regression and model-building in conservation biology, biogeography and ecology: The distinction between and reconciliation of "predictive" and "explanatory" models. Biodivers. Conserv. 9, 655-671. doi: 10.1023/A:1008985925162

Quinn, G. P., and Keough, M. J. (2002). Experimental Design and Data Analysis for Biologists, 1st Edn. Cambridge, UK: Cambridge University Press.

Sokal, R. R., and Rohlf, F. J. (2011). Biometry, 4th Edn. New York, NY: W. H. Freeman.

\section{ACKNOWLEDGMENTS}

We acknowledge support from the National Science Foundation (OCE-1458150, CCF-1442728).

Whitlock, M. C., and Schluter, D. (2008). The Analysis of Biological Data, 1st Edn. Greenwood Village, CO: Roberts and Company Publishers.

Winfree, R., Reilly, J. R., Bartomeus, I., Cariveau, D. P., Williams, N. M. and Gibbs, J. (2018). Species turnover promotes the importance of bee diversity for crop pollination at regional scales. Science 359, 791-793. doi: $10.1126 /$ science.aao2117

Zar, J. H. (1999). Biostatistical Analysis, 4th Edn. Upper Saddle River, NJ: PrenticeHall, Inc.

Conflict of Interest Statement: The authors declare that the research was conducted in the absence of any commercial or financial relationships that could be construed as a potential conflict of interest.

Copyright (c) 2019 Gouhier and Pillai. This is an open-access article distributed under the terms of the Creative Commons Attribution License (CC BY). The use, distribution or reproduction in other forums is permitted, provided the original author(s) and the copyright owner(s) are credited and that the original publication in this journal is cited, in accordance with accepted academic practice. No use, distribution or reproduction is permitted which does not comply with these terms. 